\title{
Sinipid (Hymenoptera: Cynipidae) mazlarında tespit edilen parazitoid arılar (Hymenoptera: Chalcidoidea)
}

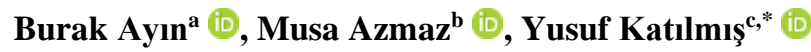

Özet: Mazı arılarıyla (Hymenoptera: Cynipidae) ilişkili parazitoid arıları tespit etmek amacıyla 2018-2019 yılları arasında Antalya ilinde arazi çalışmaları yapılmıştır. Bu çalışmalar sonucunda, dört familyaya (Eupelmidae, Eurytomidae, Torymidae ve Ormyridae) ait toplam 13 parazitoid arı türü tespit edilmiştir. Bu türlerden Torymus scutellaris (Walker, 1833) Türkiye için yeni kayıttır. Türlerin dağılımları, ilişkili oldukları mazılar ve konukçu bitkileri verilmektedir.

Anahtar kelimeler: Hymenoptera, Parazitoid, Chalcidoidea, Cynipidae, Antalya

\section{Parasitoid wasps (Hymenoptera: Chalcidoidea) found in Cynipid (Hymenoptera: Cynipidae) Galls}

\begin{abstract}
Field studies were conducted between 2018 and 2019 in Antalya province in order to reveal the parasitoid wasps associated with cynipid galls (Hymenoptera: Cynipidae). As a result of these studies, a total of 13 parasitoid wasp species were identified belonging to four families; Eupelmidae, Eurytomidae, Torymidae, and Ormyridae. Among them, Torymus scutellaris (Walker, 1833) is a new record for Turkey. Data are given on the distribution of the species, their associated galls, and host plants. Keywords: Hymenoptera, Parasitoid, Chalcidoidea, Cynipidae, Antalya
\end{abstract}

\section{Giriş}

"Parazitoid", başka bir hayvanın (konukçu) varlığında yaşayan ve sonunda onu öldüren hayvanlara denmektedir (Godfray, 1994; Gullan ve Cranston, 2014; Kaiser vd., 2017). $\mathrm{Bu}$ parazitoidler konukçusunun dişında (ektoparazitoid) veya içinde (endoparazitoid) yaşayabilirler (Godfray, 1994). Parazitoidler, gelişimlerini tamamlamak için sadece tek bir bireye ihtiyaç duyarlar ve erginleşmemiş konaklarını daima öldürürler ve ergin evrede nadiren parazittirler. Böcek yiyen (entomofaj) parazitoidler, konakları üzerinde gelişmek için birkaç yönteme sahiptirler. Ektoparazitoidler, yumurtalarını konukçunun vücudu üzerine ya da yakınına bırakırlar. Endoparazitoidler ise yumurtalarını genellikle delici bir ovipozitör (Hymenoptera takımı) yardımıyla ya da yedek bir ovipozitör (Diptera parazitoidlerde) aracılığıyla konukçunun içine bırakmaktadır (Gullan ve Cranston, 2014). Ayrıca, parazitoidler beslenme ve gelişim durumlarına göre idiobiont ve koinobiont olarak sinıflandırılır. Ídiobiont parazitoidler, konukçuyu başlangıçta hareketsiz hale getirdikten sonra daha da gelişmesini engelleyerek hemen veya kısa süre sonra konağ1 öldürür. Koinobiont parazitoidler, konukçudan beslenirken konukçunun gelişimini sürdürmesine izin verir ve sadece parazitoid gelişiminin tamamlanmasından sonra konukçu öldürülür (Hance vd., 2007). Ektoparazitoidlerin çoğu idiobiont iken, endoparazitoidler ise genellikle koinobiont canlılardır (Gullan ve Cranston, 2014). Hymenoptera (Insecta), neredeyse sadece omurgasız konukçuları kullanan parazitoid taksonların çeşitliliği ile ön plana çıkan türce zengin bir takımdır. Parazitoid arı türlerini içeren taksonlar özellikle Chalcidoidea ve Ichneumonoidea üstfamilyaları içerisinde bulunmaktadır (Gullan ve Cranston, 2014).

Mazı (gal) dokusu; mazı arılarının, fitofaj yerleşimcilerin, parazitoidlerin, hiperparazitoidlerin ve çeşitli firsatçı predatör canlıların arasında bir besin ağ oluşmasını sağlamaktadır. Böylelikle sinipid (cynipid) mazıları, kendi mazı arısının (Cynipidae) yanı sıra farklı türleri de içinde barındırmaktadır. Ekosistemde mazı arılarının büyük oranda ölümüne sebep olan canlı grupları mazı yerleşimcileri ve parazitoid arılardır (Melika, 2006). Mazı arılarına saldıran tüm parazitoid arılar çoğunlukla Chalcidoidea ve Ichneumonoidea'da yer almaktadır. Kuzey yarım kürede mazı arılarıyla beslenen yaklaşı 200 parazitoid arı türü olduğu bilinmektedir (Melika, 2006). Mazı arılarıyla beslenen çoğu parazioid arı, idiobiont ektoparazitoid olarak bilinir. Bununla birlikte, bazı parazitoid larvalarının (Eurytoma longavena Bugbee, 1951; E. brunniventris Ratzeburg, 1852; Glyphomerus stigma (Fabricius, 1793); Torymus cyaneus Walker, 1847; Dichatomus acerinus $\llbracket$ a Pamukkale Üniversitesi, Fen Bilimleri Enstitüsü, Biyoloji, Denizli, Türkiye

b Pamukkale Üniversitesi, Acıpayam Meslek Yüksekokulu, Veterinerlik Bölümü, Laborant \& Veteriner Sağlık Programı, Acıpayam, Denizli, Türkiye

c Pamukkale Üniversitesi, Fen-Edebiyat Fakültesi, Biyoloji Bölümü, Denizli, Türkiye

@ * Corresponding author (İletişim yazarı): ykatilmis@ @au.edu.tr

$\checkmark \quad$ Received (Geliş tarihi): 07.10.2021, Accepted (Kabul tarihi): 08.11.2021
Citation (Atıf): Ayın, B., Azmaz, M., Katılmıs, Y., 2021. Sinipid (Hymenoptera: Cynipidae) mazılarında tespit edilen parazitoid arılar (Hymenoptera: Chalcidoidea). Turkish Journal of Forestry, 22(4): 371-374. DOI: $10.18182 /$ tjf. 1005990 
Förster, 1878) mazı dokusuyla da beslendikleri (fakültatif fitofaji) kayıt edilmiştir. Mazı arılarına saldıran az sayıda endoparazitoid türler de bulunmaktadır: Pediobius lysis (Walker, 1839), Sycophila biguttata (Swederus, 1795), Orthopelma spp. (Ichneumonidae) (Melika, 2006).

Batı Palearktik bölgesinde mazılarla ilişkili parazitoid arıların listelendiği çalışmalar yapılmıştır (Askew vd., 2006 ve 2013). Türkiye'de ise son yıllarda yapılan çalışmalar incelendiğinde, kestane mazı arısının (Dryocosmus kuriphilus Yasumatsu) doğal düşman faunası olarak 12 parazitoid tür (Chalcidoidea) ortaya konmuştur (Doğanlar, 2014). Sonraki yıllarda yapılan çalışmalarla birlikte mazılarla ilişkili parazitoid arıların çeşitliliğine katkıda bulunulmaya devam edilmiştir (Mete ve Mergen, 2016 ve 2017; Boyadzhiev vd., 2017; Mete vd., 2018; Mete ve Lotfalizadeh, 2019). Bu çalışmayla, zengin bir tür çeşitliliğine sahip olan mazı arılarının Antalya ilinde yayılış gösteren parazitoidlerini tespit ederek ülke faunasına katkı sağlamak amaçlanmıştır.

\section{Materyal ve yöntem}

2018-2019 yılları arasında sinipid arılarının (=mazı arıları) (Hymenoptera: Cynipidae) mazıları ile ilişkili parazitoid arıları belirlemek amacıyla Antalya il sınırları içerisinde yayılış gösteren mazı arılarının oluşturduğu mazılar konukçu bitkileri (Fagaceae: Quercus aucheri Jaub. \& Spach, $Q$. coccifera L., $Q$. cerris L., $Q$. ithaburensis Decne., Q. pubescens Willd. ve Rosaceae: Rosa canina L.) üzerinden toplanmıştır. Toplanan mazıların fotoğrafları çekilmiş ve küflenmeyi önlemek için ağzı bezle kapatılan 1 L hacimli cam kavanozların içinde laboratuvara getirilmiştir. Mazı örneklerinin hangi tür tarafindan oluşturulduğu literatüre (Melika, 2006) bakılarak tespit edilmiştir. Laboratuvar koşullarında $\left(25^{\circ} \mathrm{C}\right)$ mazılardan çıkan ergin mazı arıları ve parazitoid arılar ayrılarak \%70'lik etanol içerisine alınmıştır. Parazitoid arılar, böcek yapıştırma kartlarına etiket bilgileri kaydedilerek yapıştırılmıştır. Standart müze materyali haline getirilen parazitoid arı örneklerinin teşhis işlemleri ilgili kaynaklarda (Burks, 1971; Goluet ve Huber, 1993; Graham ve Gijswijt, 1998; Zerova ve Seryogina, 1999 ve 2006; Doğanlar, 2011 ve 2017; Gibson ve Fusu, 2016) bulunan teşhis anahtarları ve tür tanımlamaları kullanılarak yapılmıştır. Teşhisi yapılan örnekler Pamukkale Üniversitesi, Fen-Edebiyat Fakültesi, Biyoloji Bölümü, Entomoloji Araştırma Laboratuvarı'nda muhafaza edilmektedir. Yeni kayıt “*” ile işaretlenmiştir.

\section{Bulgular}

Konukçu bitki üzerinden toplanan mazılardan Chalcidoidea'ye ait dört farklı familyadan (Eupelmidae, Eurytomidae, Torymidae ve Ormyridae) toplamda 13 farklı parazitoid arı türü tespit edilmiştir.

\subsection{Eupelmidae Walker, 1833}

\subsubsection{Eupelmus Dalman, 1820}

\subsubsection{Eupelmus urozonus Dalman, 1820}

İncelenen Materyal: ANTALYA, Demre, Belören, $36^{\circ} 18^{\prime} \mathrm{K}, 29^{\circ} 58^{\prime} \mathrm{D}, 612 \mathrm{~m}, 27 . \mathrm{IV} .2019$, Andricus grossulariae Giraud, 1859 mazısı, çıkış tarihi: 29.X.2019, 1; Demre, Gürses, $36^{\circ} 15^{\prime} \mathrm{K}, 29^{\circ} 56^{\prime} \mathrm{D}, 438 \mathrm{~m}, 27 . \mathrm{IV} .2019$, Andricus cecconii Kieffer, 1901 mazısı, çıkış tarihi: 23.VIII.2019, 1 \%; Demre, Karabel, 36²0'K, 295'ㄹ, 883 m, 28.X.2018, Cerroneuroterus lanuginosus (Giraud, 1859) mazısı, çıkış tarihi: 14.VII.2019, 1 ․

Konukçu Bitki: Quercus ithaburensis.

Dünya Yayılışı: Afganistan, Almanya, Amerika, Andorra, Avustralya, Avusturya, Belçika, Bosna Hersek, Bulgaristan, Cezayir, Çekya, Çin, Ermenistan, Fas, Finlandiya, Fransa, Güney Afrika, Hırvatistan, Hindistan, Hollanda, İngiltere, İran, İspanya, İsrail, İsveç, İsviçre, İtalya, Japonya, Karadağ, Kazakistan, Kıbrıs, Kore, Kuzey Afrika, Lübnan, Lüksemburg, Macaristan, Misır, Moldova, Norveç, Pakistan, Polonya, Portekiz, Romanya, Rusya, Sirbistan, Slovakya, Slovenya, Suriye, Türkiye, Ukrayna, Yunanistan (Noyes, 2019).

\subsection{Eurytomidae Walker, 1832}

\subsubsection{Eurytoma Illiger, 1807}

\subsubsection{Eurytoma caninae Lotfalizadeh \& Delvare, 2007}

İncelenen Materyal: ANTALYA, Manavgat, Kisalar, $36^{\circ} 49^{\prime} \mathrm{K}, 31^{\circ} 16^{\prime} \mathrm{D}, 6 \mathrm{~m}$, 28.IX.2018, Diplolepis fructuum (Rübsaamen, 1895) mazısı, çıkış tarihi: 11.VI.2019, 5 ㅇ․

Konukçu Bitki: Rosa canina.

Dünya Yayılışı: Fransa, İran, Fas, Türkiye, Ukrayna (Noyes, 2019).

\subsubsection{Eurytoma rosae Nees, 1834}

İncelenen Materyal: ANTALYA, Manavgat, Kısalar, $36^{\circ} 49^{\prime} \mathrm{K}, 31^{\circ} 16^{\prime} \mathrm{D}, 6 \mathrm{~m}, 28 . \mathrm{IX} .2018$, D. fructuum mazısı, çı1 1 ş tarihi: 22.X.2018, 11.VI.2019, 7 우, 1 ઈ.

Konukçu Bitki: Rosa canina.

Dünya Yayılışı: Almanya, Andorra, Arjantin, Avusturya, Belçika, Birleşik Krallık, Bulgaristan, Çekya, Çin, Ermenistan, Finlandiya, Fransa, Hollanda, İngiltere, İran, İspanya, İsveç, İsviçre, İtalya, Kazakistan, Macaristan, Malezya, Polonya, Romanya, Sirbistan, Slovakya, Türkiye, Yunanistan (Noyes, 2019).

\subsection{Ormyridae Foerster, 1856}

\subsubsection{Ormyrus Westwood, 1832}

\subsubsection{Ormyrus nitidulus Fabricius, 1804}

İncelenen Materyal: ANTALYA, Demre, Belören, $36^{\circ} 18^{\prime} \mathrm{K}, 29^{\circ} 58^{\prime} \mathrm{D}, 627 \mathrm{~m}$, 28.IX.2018, Pseudoneuroterus

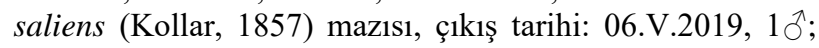
Demre, Gürses, $36^{\circ} 15^{\prime} \mathrm{K}, 29^{\circ} 56^{\prime} \mathrm{D}, 438$ m, 27.IV.2019, Plagiotrochus quercusilicis (Fabricius, 1798) mazısı, çıkış tarihi: 07.IX.2019, $3 \delta^{\Uparrow} \delta^{\lambda}$; Manavgat, Gündoğdu, 36 50'K, 
$31^{\circ} 16^{\prime} \mathrm{D}, 30 \mathrm{~m}, 28 . I V .2019$, Andricus infectorius (Hartig, 1843) mazısı, çıkış tarihi: 03.IX.2019, 1 q.

Konukçu Bitki: Quercus coccifera, Q. ithaburensis, $Q$. pubescens.

Dünya Yayılışı: Almanya, Amerika, Andorra, Avusturya, Azerbaycan, Belçika, Birleşik Krallık, Bosna Hersek, Bulgaristan, Cezayir, Çekya, Danimarka, Fransa, Gürcistan, Hırvatistan, Hollanda, İngiltere, İran, İspanya, İsveç, İsviçre, İtalya, Kuzey Afrika, Macaristan, Makedonya, Romanya, Sirbistan, Slovakya, Türkiye, Ukrayna, Ürdün, Yunanistan (Noyes, 2019).

\subsubsection{Ormyrus pomaceus Geoffroy, 1785}

İncelenen Materyal: ANTALYA, Alanya, Bayırköy, $36^{\circ} 43^{\prime} \mathrm{K}, 31^{\circ} 56^{\prime} \mathrm{D}, 760 \mathrm{~m}, 24 . \mathrm{XI} .2018$, Aphelonyx cerricola (Giraud, 1859) mazısı, çıkış tarihi: 22.VI.2019, 4우우, $3 \widehat{0}$ ठ․

Konukçu Bitki: Quercus ithaburensis.

Dünya Yayılışı: Almanya, Andorra, Avusturya, Birleşik Krallık, Bulgaristan, Çekya, Danimarka, Finlandiya, Fransa, Güney Kore, Hirvatistan, Hollanda, Karadağ, İngiltere, İran, İrlanda, İspanya, İsveç, İtalya, Japonya, Macaristan, Polonya, Rusya, Romanya, Surbistan, Slovakya, Türkiye, Ukrayna, Ürdün, Yunanistan (Noyes, 2019).

\subsection{Torymidae Walker, 1833}

\subsubsection{Glyphomerus Foerster, 1856}

\subsubsection{Glyphomerus stigma Fabricius, 1793}

İncelenen Materyal: ANTALYA, Manavgat, Kısalar, $36^{\circ} 49^{\prime} \mathrm{K}, 31^{\circ} 16^{\prime} \mathrm{D}, 6 \mathrm{~m}, 28 . \mathrm{IX} .2018$, D. fructuum mazısı, çıkış

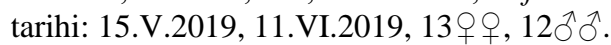

Konukçu Bitki: Rosa canina.

Dünya Yayılışı: Almanya, Amerika, Andora, Avusturya, Birleşik Krallık, Bulgaristan, Çekya, Fransa, Hırvatistan, Hollanda, İngiltere, İran, İspanya, İsveç, İsviçre, İtalya, Japonya, Kanada, Kırgizistan, Macaristan, Romanya, Rusya, Sirbistan, Slovakya, Türkiye, Ukrayna, Yunanistan (Noyes, 2019).

\subsubsection{Bootanomyia Girault, 1915}

\subsubsection{Bootanomyia almusiensis (Doğanlar, 1989)}

İncelenen Materyal: ANTALYA, Demre, Karabel, $36^{\circ} 20^{\prime} \mathrm{K}, 29^{\circ} 56^{\prime} \mathrm{D}, 883 \mathrm{~m}, 28 . X .2018$, Andricus istvani Melika, 2008 mazısı, çıkış tarihi: 07.IX.2019, 2 우.

Konukçu Bitki: Quercus ithaburensis.

Dünya Yayılışı: İran, Türkiye (Noyes, 2019).

\subsubsection{Bootanomyia dorsalis (Fabricius, 1798)}

İncelenen Materyal: ANTALYA, Demre, Davazlar, $36^{\circ} 15^{\prime} \mathrm{K}, 29^{\circ} 54^{\prime} \mathrm{D}, 552 \mathrm{~m}, 27 . I \mathrm{~V} .2019$, Chilaspis israeli

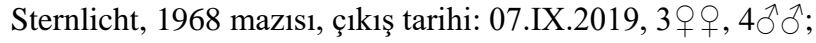
Gündoğmuş, Akyar, 36²44'K, 32¹2'D, 720 m, 24.XI.2018, Synophrus politus Hartig, 1843 mazısı, çıkış tarihi: 08.VII.2019, $1 \hat{\jmath}$.

Konukçu Bitki: Quercus ithaburensis.

Dünya Yayılışı: Almanya, Andora, Avusturya, Belçika, Birleşik Krallık, Bosna Hersek, Bulgaristan, Çekya, Çin, Danimarka, Fransa, Hirvatistan, Hindistan, Hollanda,
İngiltere, İran, İsrail, İspanya, İsveç, İtalya, Macaristan, Makedonya, Moldovya, Portekiz, Romanya, Rusya, Sirbistan, Slovakya, Tunus, Türkiye, Ukrayna, Yunanistan (Noyes, 2019).

\subsubsection{Bootanomyia synophri (Mayr, 1874)}

İncelenen Materyal: ANTALYA, Alanya, Dim Baraj1, $36^{\circ} 33^{\prime} \mathrm{K}, 32^{\circ} 08^{\prime} \mathrm{D}, 140 \mathrm{~m}$, 04.VIII.2018, S. politus mazıs1, çıkış tarihi: 22.X.2018, 3 q ; Demre, Belören, 36² $18^{\prime} \mathrm{K}$, 2958'D, 612 m, 27.IV.2019, S. politus mazısı, çıkış tarihi: 06.IX.2019, 1 우으. 1 .

Konukçu Bitki: Quercus cerris.

Dünya Yayılıșı: Avusturya, Bulgaristan, Cezayir, Macaristan, Türkiye, Yunanistan (Noyes, 2019).

\subsubsection{Megastigmus Dalman, 1820}

\subsubsection{Megastigmus rosae Bouček, 1971}

İncelenen Materyal: ANTALYA, Manavgat, Kısalar, $36^{\circ} 49^{\prime} \mathrm{K}, 31^{\circ} 16^{\prime} \mathrm{D}, 6 \mathrm{~m}$, 28.IX.2018, D. fructuum mazısı, çıkış tarihi: 11.VI.2019, 1 .

Konukçu Bitki: Rosa canina.

Dünya Yayılışı: Almanya, Avusturya, Azerbaycan, Çekya, Ermenistan, Fransa, Gürcistan, İran, İsviçre, Kazakistan, Rusya, Tacikistan, Türkiye, Türkmenistan, Ukrayna (Noyes, 2019).

\subsubsection{Torymus Dalman, 1820}

\subsubsection{Torymus bedeguaris (Linnaeus, 1758)}

İncelenen Materyal: ANTALYA, Manavgat, Gündoğdu, $36^{\circ} 50^{\prime} \mathrm{K}, \quad 31^{\circ} 16^{\prime} \mathrm{D}, \quad 17 \mathrm{~m}, \quad 30 . \mathrm{III} .2019$, Neuroterus quercusbaccarum (Linnaeus, 1758) mazısı, çıkış tarihi:

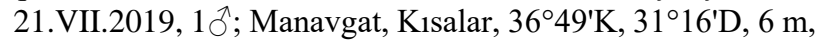
28.IX.2018, D. fructuum mazısı, çıkış tarihi 22.X.2018,

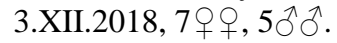

Konukçu Bitki: Quercus ithaburensis, Rosa canina.

Dünya Yayılışı: Almanya, Amerika, Andora, Avusturya, Azerbaycan, Belçika, Birleşik Krallık, Bulgaristan, Çekya, Çin, Danimarka, Ermenistan, Fransa, Gürcistan, Hırvatistan, Hollanda, İngiltere, İran, İspanya, İsveç, İsviçre, İtalya, Kanada, Kazakistan, Kırgızistan, Macaristan, Moldovya, Romanya, Rusya, Sirbistan, Slovakya, Tacikistan, Türkiye, Türkmenistan, Ukrayna, Yunanistan (Noyes, 2019).

\subsubsection{Torymus flavipes (Walker, 1833)}

İncelenen Materyal: ANTALYA, Alanya, Bayırköy, $36^{\circ} 43^{\prime} \mathrm{K}, 31^{\circ} 56^{\prime} \mathrm{D}, 760 \mathrm{~m}, 24 . \mathrm{XI} .2018$, Ap. cerricola mazis1,

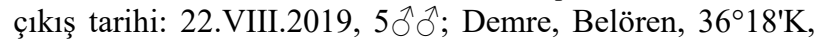
2958'D, 612 m, 27.IV.2019, A. grossulariae mazısı, çıkış

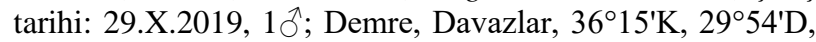
552 m, 27.IV.2019, Ch. israeli mazısı, çıkış tarihi:

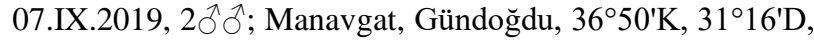
17 m, 30.III.2019, N. quercusbaccarum mazısı, çıkış tarihi:

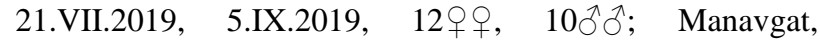
Gündoğdu, $36^{\circ} 50^{\prime} \mathrm{K}, 31^{\circ} 16^{\prime} \mathrm{D}, 30 \mathrm{~m}$, 28.IV.2019, Biorhiza pallida (Olivier, 1791) mazısı, çıkış tarihi: 7.IX.2019, 1 q.

Konukçu Bitki: Quercus cerris, Q. ithaburensis, $Q$. pubescens. 
Dünya Yayılışı: Almanya, Amerika, Andora, Avusturya, Azerbaycan, Belçika, Birleşik Krallık, Bulgaristan, Çekya, Çin, Finlandiya, Fransa, Hırvatistan, Hollanda, İngiltere, İskoçya, İspanya, İsrail, İsveç, İsviçre, İtalya, Macaristan, Polonya, Romanya, Rusya, Slovakya, Slovenya, Türkiye, Ukrayna (Noyes, 2019).

\subsubsection{Torymus scutellaris (Walker, 1833)*}

İncelenen Materyal: ANTALYA, Manavgat, Gündoğdu, $36^{\circ} 50^{\prime} \mathrm{K}, 31^{\circ} 16^{\prime} \mathrm{D}, 17 \mathrm{~m}, 30 . \mathrm{III} .2019$, N. quercusbaccarum mazısı, çıkış tarihi 21.VII.2019, 25.X.2019, 5 ふో

Konukçu Bitki: Quercus pubescens.

Dünya Yayılışı: Almanya, Birleşik Krallık, Danimarka, Fransa, Hollanda, İngiltere, İsveç, İtalya, Moldova, Romanya (Noyes, 2019).

\section{Tartışma ve sonuç}

Arazi çalışmaları neticesinde konukçu bitkiler üzerinden toplam 20 farklı türe ait sinipid mazısı toplanmıştır. Diplolepis fructuum mazısından 5 farklı parazitoid arı türü, Neuroterus quercusbaccarum mazisından ise 3 farklı parazitoid arı türü tespit edilmiştir. Aphelonyx cerricola, Andricus grossulariae, Chilaspis israeli ve Synophrus politus mazılarından ikişer parazitoid arı türü, Andricus infectorius, Andricus istvani, Andricus cecconii, Biorhiza pallida, Cerroneuroterus lanuginosus, Pseudoneuroterus saliens ve Plagiotrochus quercusilicis mazılarından ise birer parazitoid arı türü tespit edilmiştir. Parazitoid türlerin farklı mazılarda görülme dağılımına bakıldığında; Torymus flavipes beş mazı türünde, Eupelmus urozunos ve Ormyrus nitidulus üç mazı türünde, Bootanomyia almusiensis ve Torymus bedeguaris iki mazı türünde, Bootanomyia dorsalis, Bootanomyia synophri, Eurytoma caninae, Eurytoma rosae, Glyphomerus stigma, Ormyrus pomaceus, Megastigmus rosae ve Torymus scutellaris ise bir mazı türünde tespit edilmiştir.

Çalışma sonucunda, T. scutellaris türünün Türkiye için yeni kayıt olduğu ve ilk kez $N$. quercusbaccarum arısı tarafından oluşturulan mazı ile ilişkili olduğu tespit edilmiştir. Bunun yanı sıra, çalışma alanında tespit edilen 13 türün tamamı Antalya ilinden ilk kez bu çalışma ile kaydedilmiştir. Yapılacak yeni ve kapsamlı çalışmalar ile Cynipidae türleri ile ilişkili parazitoid tür sayısının daha fazla artması beklenmektedir.

\section{Açıklama}

Çalışmaya olan katkıları ve teşhis işlemlerindeki yardımlarından dolay1 Araş. Gör. Dr. Özlem METE’ye (Hacettepe Üniversitesi, Fen Fakültesi, Biyoloji Bölümü) teşekkürlerimizi sunarız. Çalışma bir yüksek lisans tezinden üretilmiş ve Pamukkale Üniversitesi, Bilimsel Araştırma Projeleri tarafindan 2018FEBE034 numaralı proje ile desteklenmiştir.

\section{Kaynaklar}

Askew, R.R., Plantard, O., Gómez, J.F., Nieves, M.H., Nieves-Aldrey, J.L., 2006. Catalogue of parasitoids and inquilines in galls of Aylacini, Diplolepidini and Pediaspidini (Hym., Cynipidae) in the West Palaearctic. Zootaxa, 1301: 1-60.

Askew, R.R., Melika, G., Pujade-Villar, J., Schönrogge, K., Stone, G.N., 2013. Catalogue of parasitoids and inquilines in cynipid oak galls in the West Palaearctic. Zootaxa, 3643(1): 1-133.

Boyadzhiev, P.S., Yefremova, Z.A., Tozlu, G., Mergen, Y.O., Mete, O., 2017. Description of Stepanovia fructirosae sp. n. (Hymenoptera: Chalcidoidea: Eulophidae) from Turkey. Acta Zoologica Bulgarica, Supplement 8: 113-117.

Burks, B.D., 1971. A synopsis of the genera of the family Eurytomidae (Hymenoptera: Chalcidoidea). Transactions of the American Entomological Society, 97(1): 1-89.

Doğanlar, M., 2011. Review of Palearctic and Australian species of Bootanomyia Girault 1915 (Hymenoptera: Torymidae: Megastigminae), with descriptions of new species. Turkish Journal of Zoology, 35(2): 123-157.

Doğanlar, M., 2014. Yalova'da (Türkiye) Kestane gal arısı, Dryocosmus kuriphilus Yasumatsu (Hymenoptera: Cynipidae) nin doğal düşman faunası hakkında ilk kayıtlar. Türkiye Biyolojik Mücadele Dergisi, 5(1): 67-74

Doğanlar, M., 2017. Turkish species of Torymus Dalman, 1820 (Hymenoptera: Torymidae: Torymini), with descriptions of new species. Munis Entomology \& Zoology, 12(1): 5-22.

Gibson, A.P.G., Fusu, L., 2016. Revision of the Palaearctic species of Eupelmus (Eupelmus) Dalman (Hymenoptera: Chalcidoiadea: Eupelmidae). Zootaxa, 4081(1): 1-331.

Godfray, H.C.J., 1994. Parasitoids, Behavioral and Evolutionary Ecology. Princeton, NJ: Princeton University Press.

Goulet, H., Huber, J.T., 1993. Hymenoptera of the World: An identification guide to families. Agriculture Canada, Ottawa, Ontario, John Wiley and Sons.

Graham, M.W.R., Gijswijt, M.J., 1998. Revision of the European species of Torymus Dalman (Hymenoptera: Torymidae). Zoologische Verhandelingen, 317: 1-202.

Gullan, P.J., Cranston, P.S., 2014. The Insects: An Outline of Entomology (5th ed.). Wiley-Blackwell.

Hance, T., van Baaren, J., Vernon, P., Boivin, G., 2007. Impact of extreme temperatures of parasitoids in a climate change perspective. Annual Review of Entomology, 52: 107-126.

Kaiser, L., Ode, P., van Nouhuys, S., Calatayud, P.-A., Colazza, S., Cortesero, A.-M., Thiel, A., van Baaren, J., 2017. The plant as a habitat for entomophagous insects. Advances in Botanical Research, 81: 179-223.

Melika, G., 2006. Gall Wasps of Ukraine, Cynipidae. Vestnik Zoologii, 21(1-2): 1-644.

Mete, Ö., Azmaz, M., Lotfalizadeh, H., Katılmış, Y., 2018. Some records of parasitoid wasps associated with gall wasps (Hymenoptera: Cynipidae) in Istanbul, Turkey. Munis Entomology \& Zoology, 13(2): 542-547.

Mete, Ö., Lotfalizadeh, H., 2019. Parasitoid wasps associated with Diplolepis galls (Hymenoptera: Cynipidae) in Turkey: an updated checklist and report of three non-regular species. Phytoparasitica, 47: 361-374.

Mete, Ö., Mergen, Y.O., 2016. The community members associated with rose gall wasp Diplolepis fructuum (Rübsaamen, 1895) (Hymenoptera: Cynipidae) in Tokat Province of Turkey. Turkish Journal of Zoology, 40(3): 411-416.

Mete, Ö., Mergen, Y.O., 2017. The community components associated with two common rose gall wasps (Hymenoptera: Cynipidae: Diplolepidini) in Turkey. Turkish Journal of Zoology, 41: 696-701.

Noyes, J.S., 2019. Universal Chalcidoidea Database. World Wide Web electronic publication. http://www.nhm.ac.uk/chalcidoids, Accessed: 01.09.2021.

Zerova, M.D., Seryogina L.Y., 1999. A review of Palearctic species of the Genus Glyphomerus (Hymenoptera, Torymidae) with description of two new species. Entomological Review, 79(8): 977981.

Zerova, M.D., Seryogina, L.Y., 2006. Review of Palearctic ormyridae (Hymenoptera, Chalcidoidea), with description of two new species. Vestnik zoologii, 40(1): 27-40. 